\title{
Research Paper: The Effectiveness of Narrative Exposure Therapy on Improving Posttraumatic Symptoms and Interpersonal Reactivity in Patients With Cancer
}

\author{
*Sajad Basharpoor ${ }^{1} \odot$, Sholeh Amani ${ }^{1 \oplus}$, Mohammad Narimani ${ }^{1}$ (1)
}

1. Department of Psychology, Faculty of Educational Science and Psychology, University of Mohaghegh Ardabil, Ardabil, Iran.

\begin{tabular}{|c|c|c|}
\hline $\begin{array}{c}\text { Use your device to scan } \\
\text { and read the article online }\end{array}$ & $\begin{array}{l}\text { Citation Basharpoor S, Amani Sh, Narimani M. [The Effectiveness of Narrative Exposure Therapy on Improving Posttraumatic } \\
\text { Symptoms and Interpersonal Reactivity in Patients With Cancer (Persian)]. Archives of Rehabilitation. 2019; 20(3):230-241. } \\
\text { http://dx.doi.org/10.32598/rj.20.3.230 }\end{array}$ \\
dol' http://dx.doi.org/10.32598/rj.20.3.230
\end{tabular}

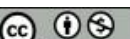

Received: 30 Apr 2019

Accepted: 28 Aug 2019

Available Online: 01 Oct 2019
Keywords:

Narrative Exposure Therapy (NET),

Post-Traumatic Stress

Disorder (PTSD), Post-

traumatic, Reactivity,

Cancer

\section{ABSTRACT}

Objective As a universal problem, cancer is the third cause of deaths in Iran. Recent advances in the treatment of this disease have been led to the prolonged life of these patients and increased the importance of paying attention to their psychological adaptation to the disease. Since the disease is a threat to individual life, perceiving the diagnosis of this disease can cause post-traumatic symptoms and intensify the psychological reactivity of the individual. This study conducted in order to investigate the effectiveness of Narrative Exposure Therapy (NET) on reducing the post-traumatic symptoms and interpersonal reactivity in patients with cancer.

Materials \& Methods This research is a pilot experimental study with pretest-posttest design with a control group. The statistical population of this study included all female cancer patients with Post-Traumatic Stress Disorder (PTSD), admitted to the Blood and Oncology Department of Motahari Hospital of Foulad Shahr of Isfahan from July to September of 2016, and had completed complementary and maintenance chemotherapy and radiology treatments. To select the subjects, the list of all patients with cancer diagnosis was obtained and after referring them to the site of the section and explaining the goals of this research, the scale of PTSD and the interpersonal reactivity were conducted to the all 63 hospitalizations and after collecting data, 30 of these people who had a score higher than 65 in the scale of Mississippi PTSD, and had malignant diagnosis were selected. In the next stage, structured clinical interviews, on the basis of DSM-5 criteria for the diagnosis of PTSD symptoms, and after confirmation of diagnosis, subjects were assigned to experimental group $(n=15)$ and control group $(n=15)$. The experimental group received 6 sessions of 90 minutes of NET, but the control group received no treatment. Collected data were analyzed by MANCOVA and ANCOVA tests using SPSS 18 software.

Results According to the results, after controlling for the pre-test effects, there was a significant difference between the mean scores of the two groups in the total score of the PTSD scale and the components of malicious memories, interpersonal communication, emotion control, depression, and two interactive reactivity components, namely, empathy and personal discomfort exist $(\mathrm{P}<0.05)$ indicating that NET has been effective in reducing symptoms of traumatic stress disorder and empathy and improving personal empathy and discomfort in cancer patients. But according to the results in the fantasy subscales, having a broad vision and overall stress response score did not find a significant difference between the two groups.

Conclusion The results of this study revealed that NET can be an appropriate therapeutic program for reducing post-traumatic symptoms in patients with cancer because this intervention is based on the expression and retrieval of the traumatic event's details in a safe environment of therapy, but this intervention has less effect on interpersonal reactivity. Based on these results, it can be recommended using this intervention as an effective method for improvement of psychological problems related to diagnosing cancer along with biological treatments in patients with cancer.

\section{* Corresponding Author:}

Sajjad Basharpoor, PhD.

Address: Department of psychology, Faculty of Educational Science and Psychology, University of Mohaghegh Ardabil, Ardabil, Iran.

Tel: +98 (45) 33515629

E-Mail: basharpoor_sajjad@uma.ac.ir 


\title{
اثربخشى مواجهلهدرمانى روايتى بر بهبود علائم يسآسيبى و واكنش يذيرى بينفردى در بيماران مبتلابه سرطان
}

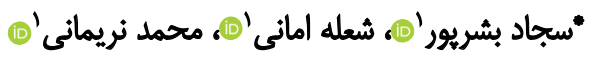 \\ ا - كروه روانشئاسى، دانشكده علوم تربيتى و روانشناسى، دانشغاه محقق اردبيلى، اردبيل، ايران.
}

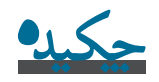

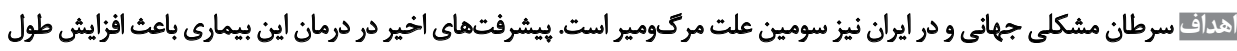

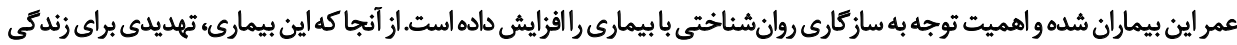

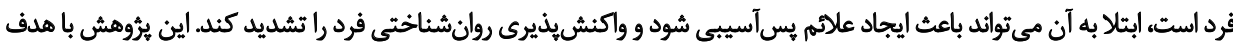

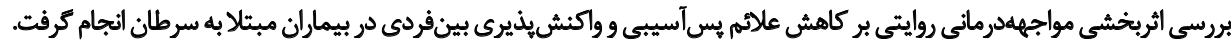

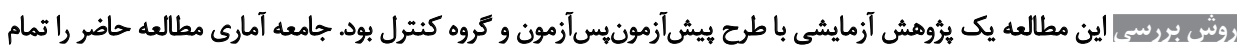

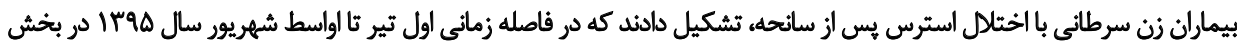

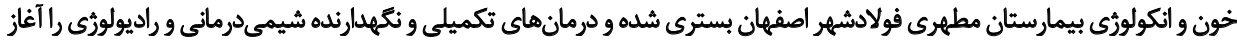

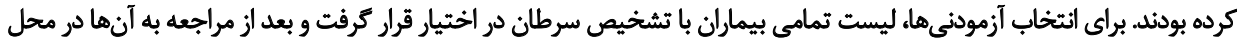

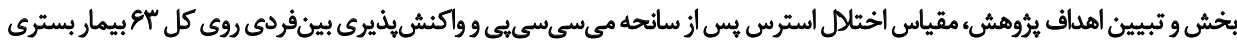

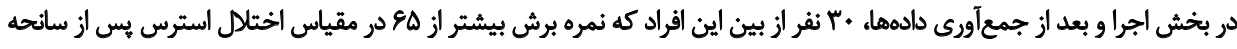

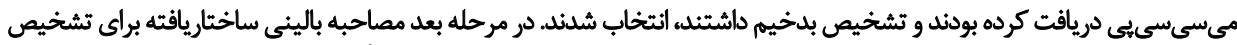

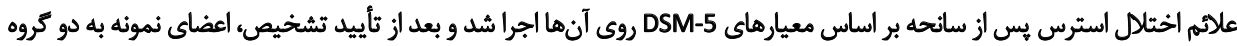

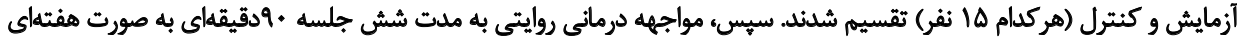

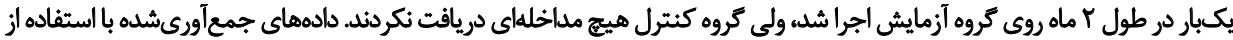

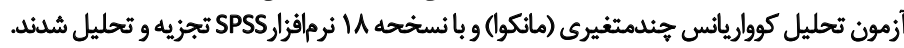

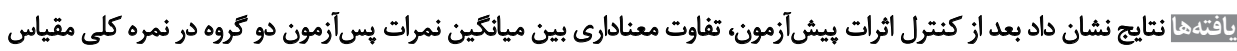

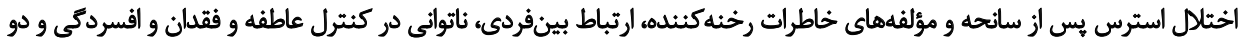

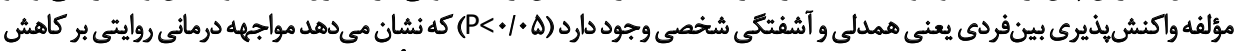

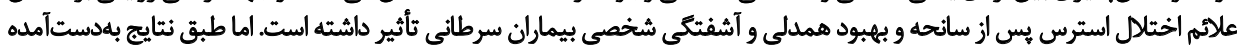

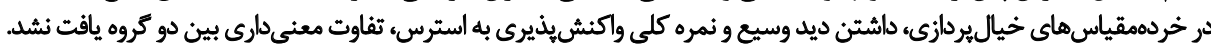

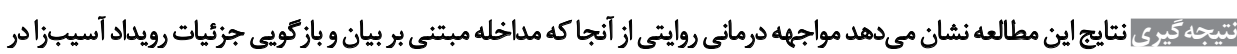

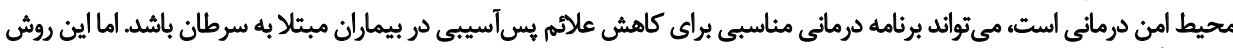

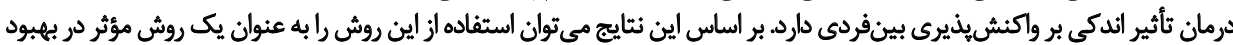

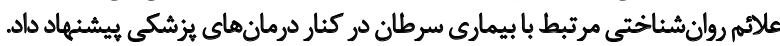

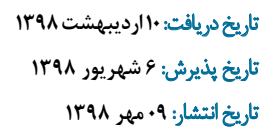

كليدواروها:

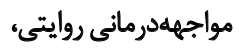

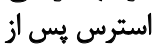

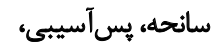
واكنشيذيرى، سرطان

سرانجام موجب متاستاز ' و كسترش در كل بدن از طريق سيستم

مقدمه

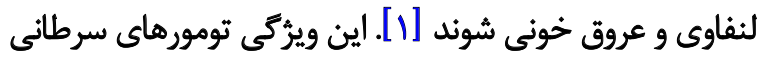

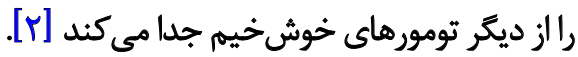
با وجود يِيشفتهاى درخور توجه علم يزشكى، سرطان سرطان' شاخهاى از بيمارىهاست كه در آن كروهى از

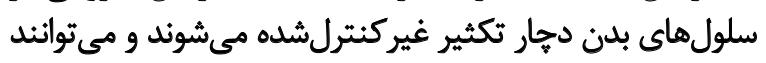

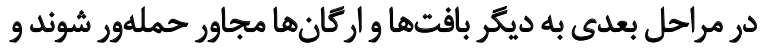




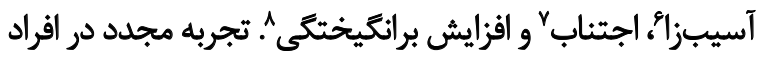

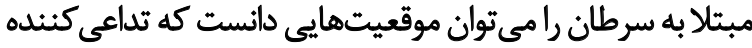

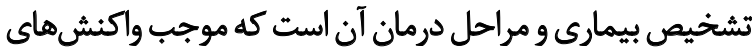

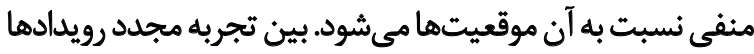

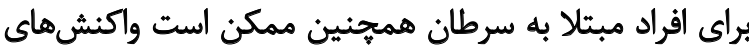

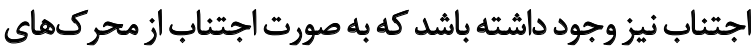

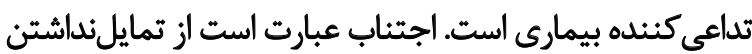

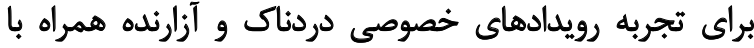

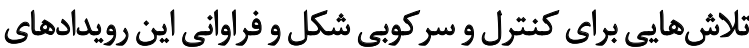

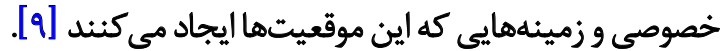

اسميت" در يُوهشى دريافت كه اجتناب باعث بسيارى از ازئي

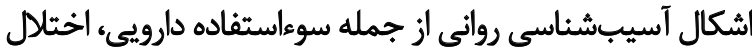

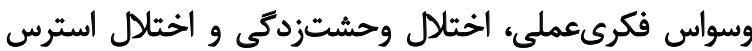

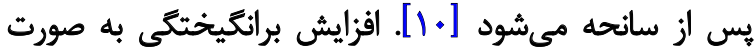

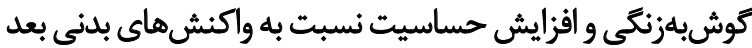

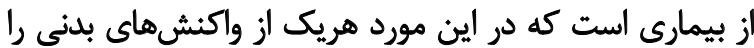

نشانه بيمارى در نظر مي كيرند [11]

به طور كلى، تشخيص سرطان، موجب بروز مشكلات

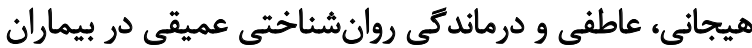

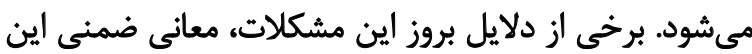

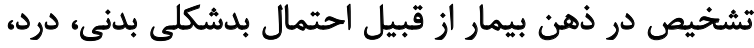

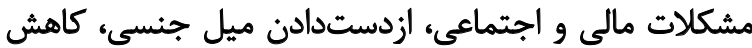

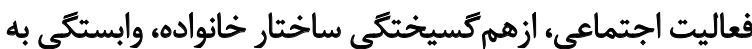

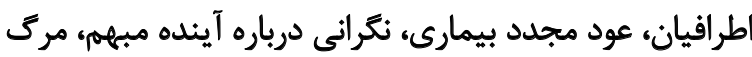

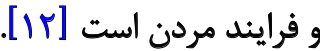

تمامى اين مشكلات و مسائل مربوط به تشخيص و درمان

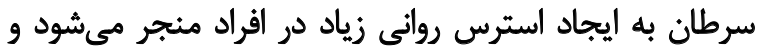

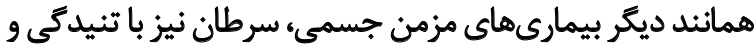

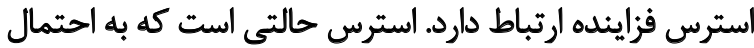

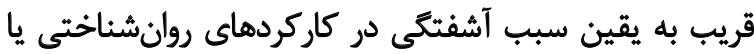

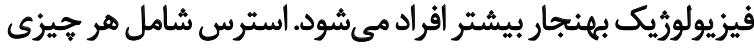

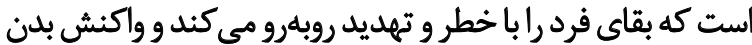

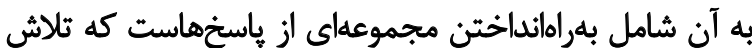

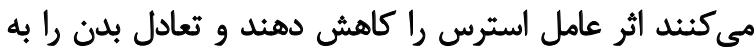

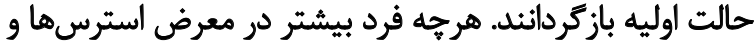

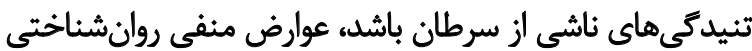

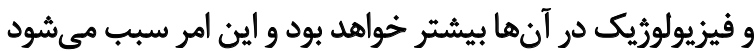

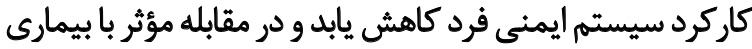

دجار مشكل شود [بارئ.

6. Re-experiencing

7. Avoidance

8. Increased arousal

9. Smith
همجنان به عنوان يكى از مهمترين بيمارىهاى قرن، در بين

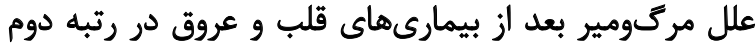

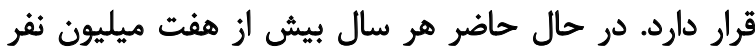

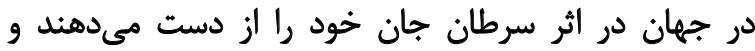

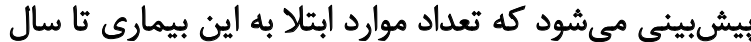

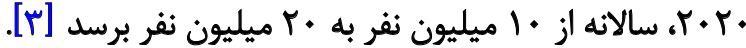

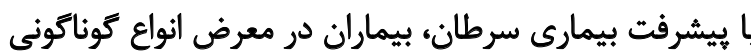

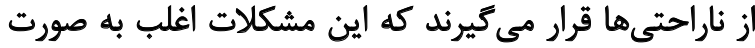

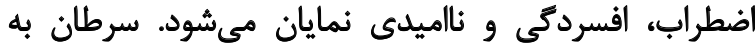

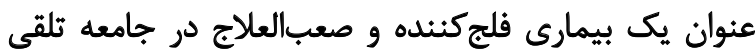

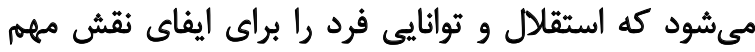

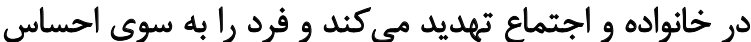

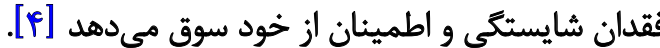

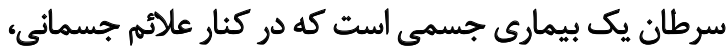

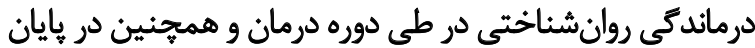

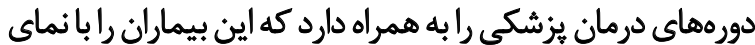

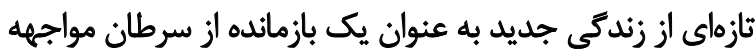

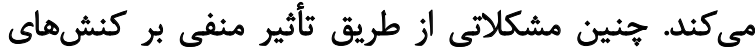

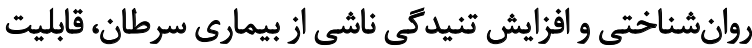

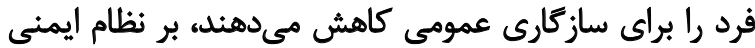

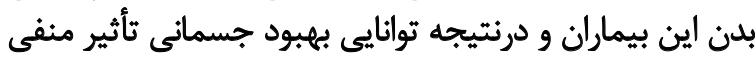

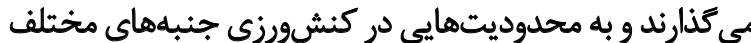

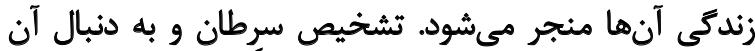

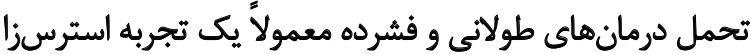

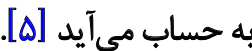

انجمن روانيزشكى آمريكا" در سال 1994 براى اولينبار

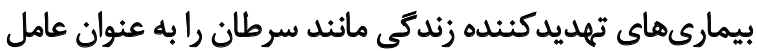

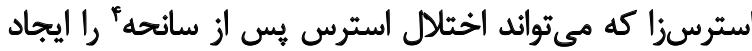

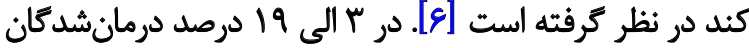

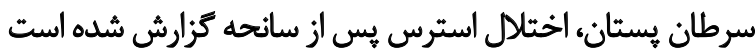

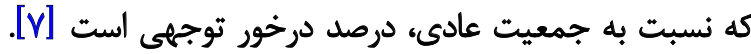

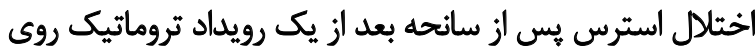

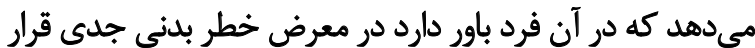

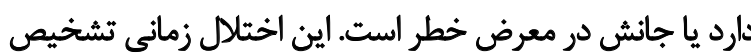

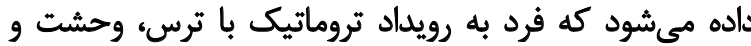

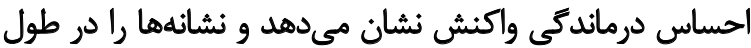

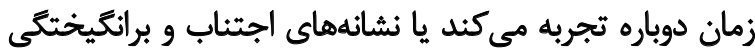

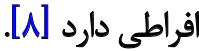

نشائههاى اختلال استرس يس از سانحه به هجار دسته تقسيم

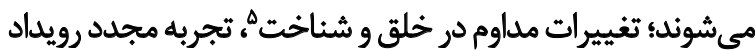

3. American Psychiatric Association (APA)

4. Post-traumatic Stress Disorder

5. Constant changes in mood and cognitive 


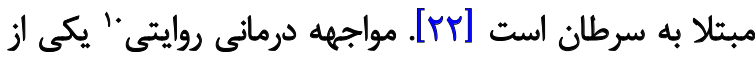

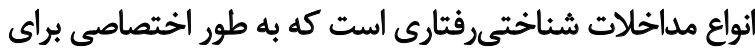

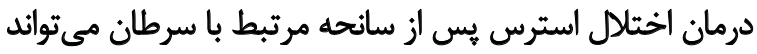

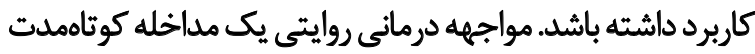

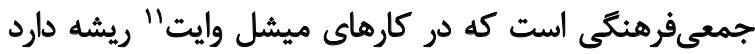

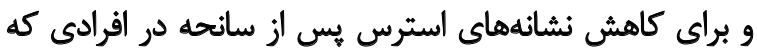

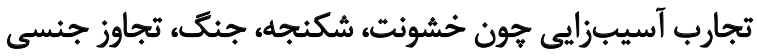

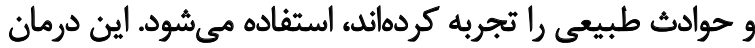

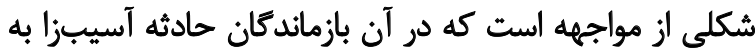

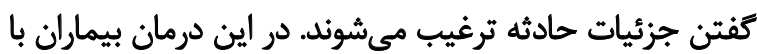

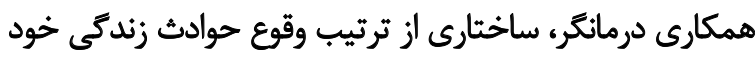

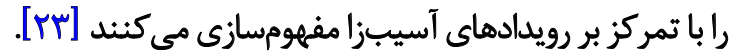

يافتهاى يُروهشى نشان مي دهد مردم بخش زيادى از

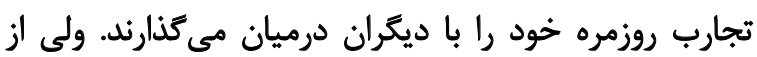

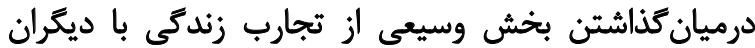

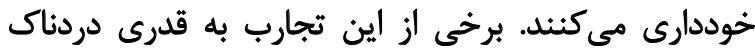

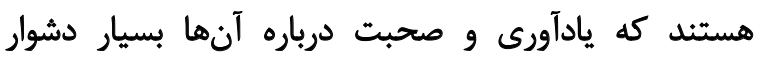

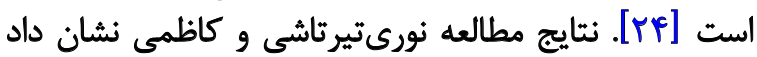

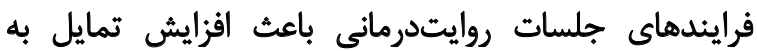

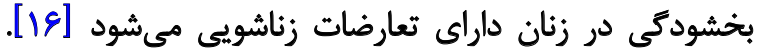

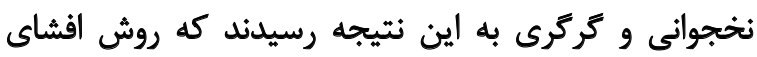

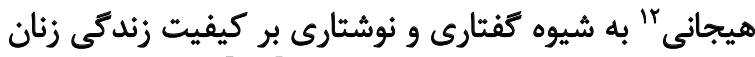

مبتلا به سرطان سينه مؤثر بوده است [1/11]

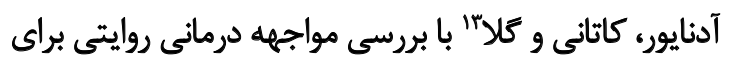

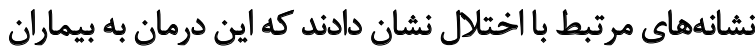

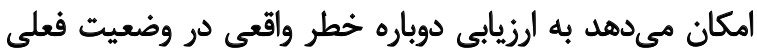

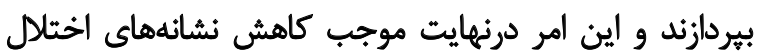

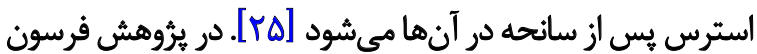

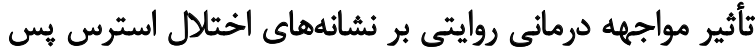

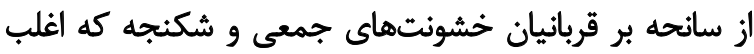

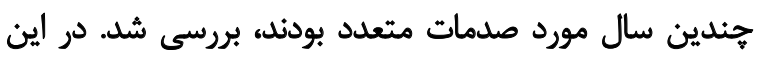

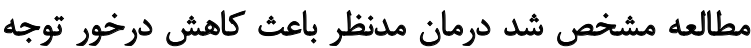

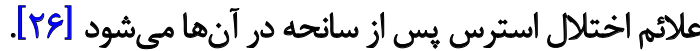

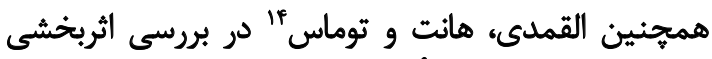

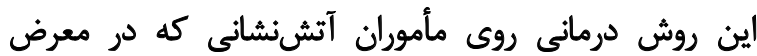

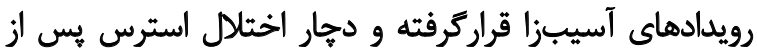

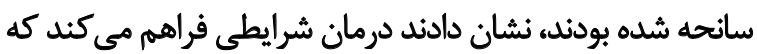

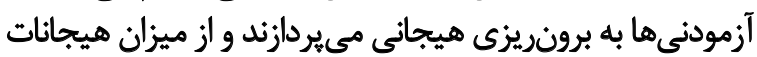

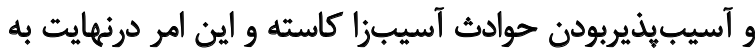

10. Narrative Exposure Therapy

11. Micheal Whight

12. Emotional Disclosure

13. Adenaur, Catani \&Gela

14. Alghamdi , Hant \& Thomas
اين بيمارى، مزمن و تهديدكنيده زندكى است و تأثيرات

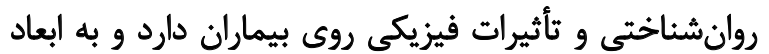

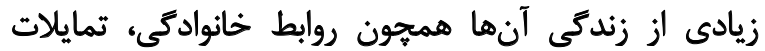

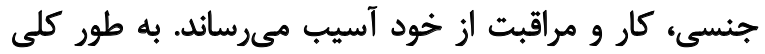

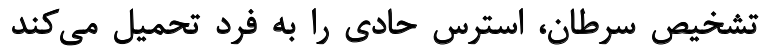

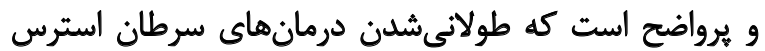

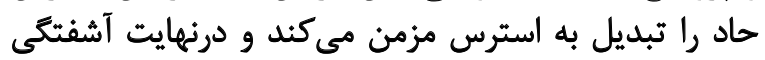

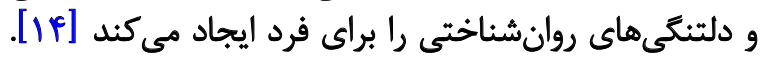

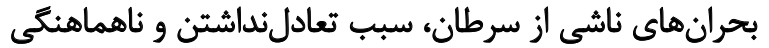

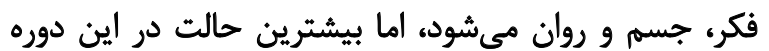

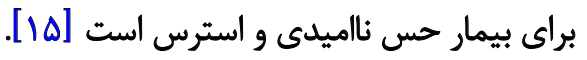
نورى ثيرثاشى و كاظمى در يُوهشى به اين نتيجه رسيدند

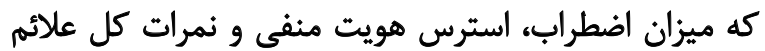

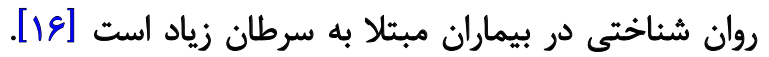

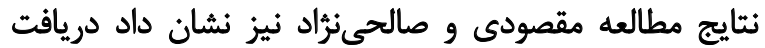

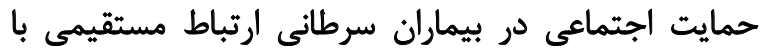

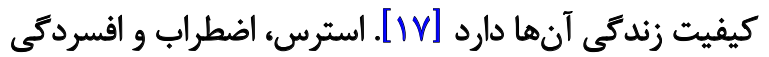

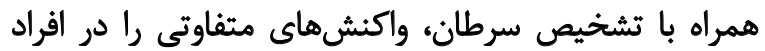

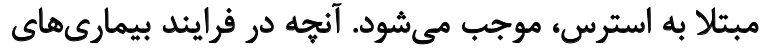

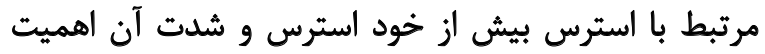

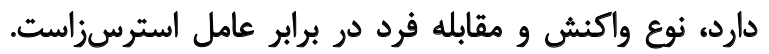

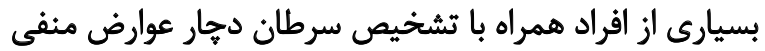

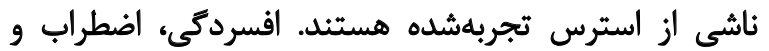

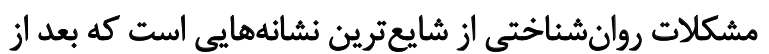
تشخيص سرطان كزارش شده است [11 [11].

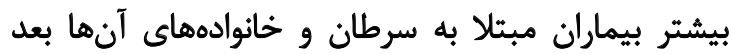

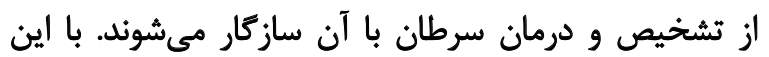

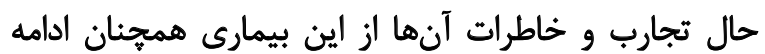

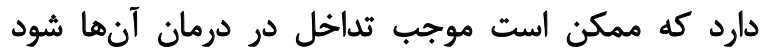

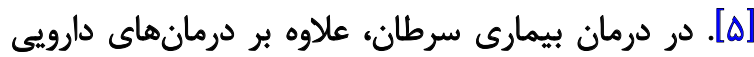

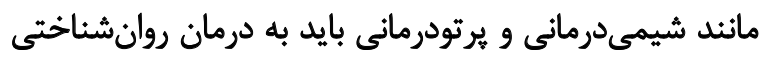

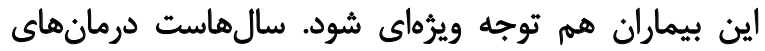

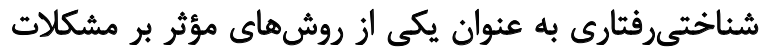

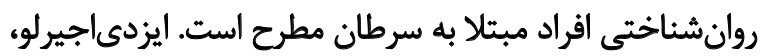

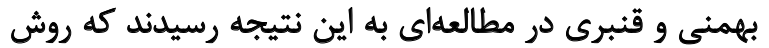

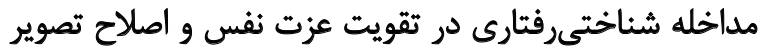
بدن در زنان مبتلا به سرطان سينه مؤثر است [ب. [ب] امانى، مظاهرى، نجاتى و شمسيان نشان دادند توانبخشى

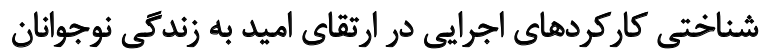

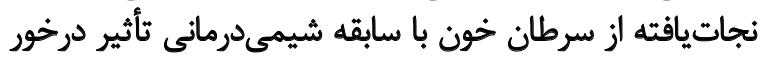

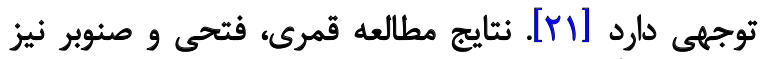
حاكى از تأثير تصويرسازى ذهنى بر كاهش خشائ خشم كودكان 


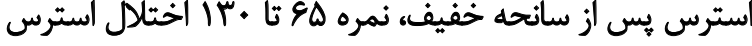

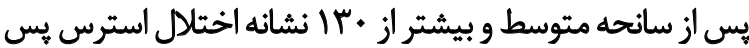

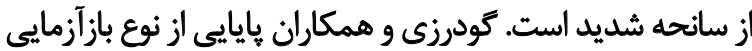

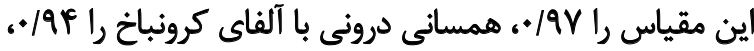

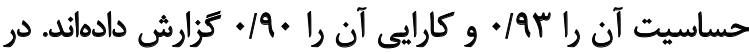

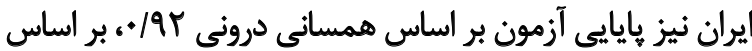

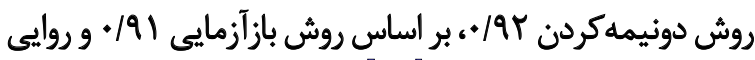

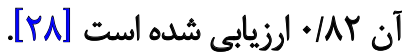

\section{شاخصص واكنش ئذيرى بين فردى}

شاخص واكنشيذيرى بين فردى را ديويس لا به منظور

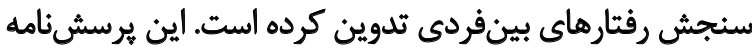

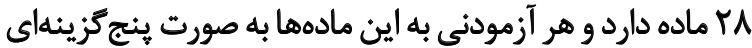

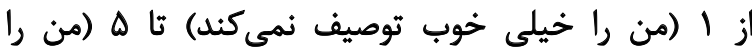

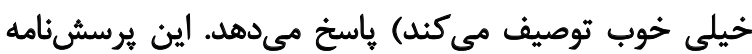

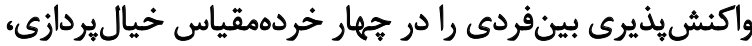

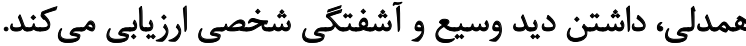

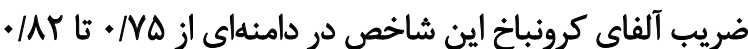

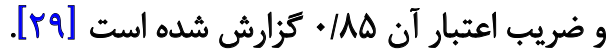

$$
\text { وإش كار }
$$

روند جمعآورى اطلاعات در اين مطالعه به اين صورت بود

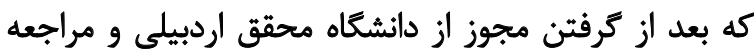

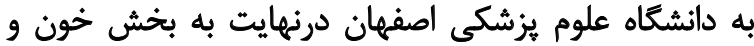

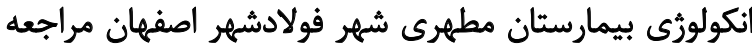

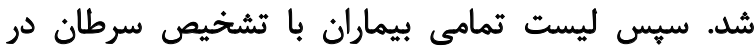

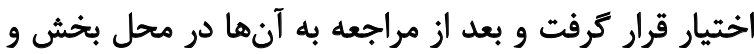

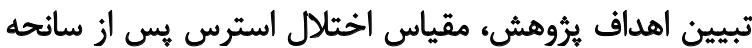

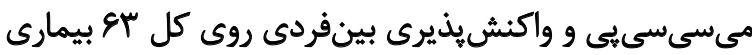

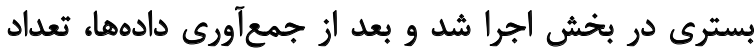

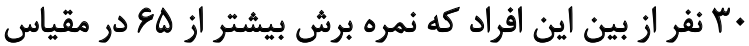

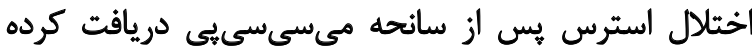

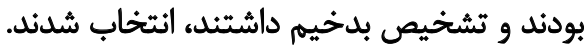

در مرحله بعد مصاحبه بالينى ساختاريافته براى تشخيص

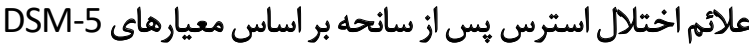

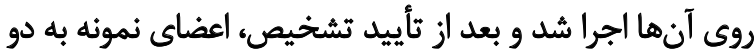

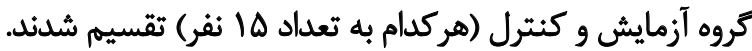

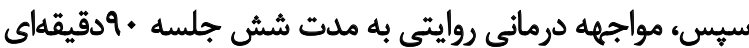

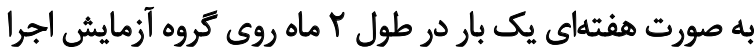

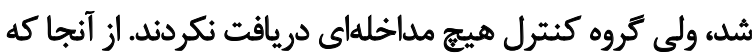

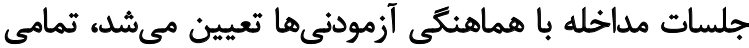

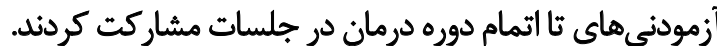

\section{Daivis}

كاهش علائم كلى آنها منجر مي شود [YY]].

درمجموع، شواهد موجود نشان ميدهد بيماران مبتلا به إنه

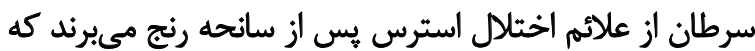

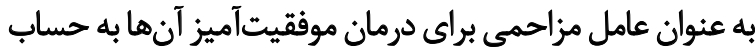

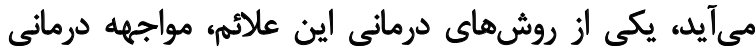

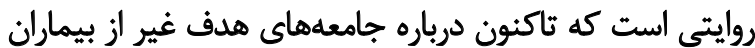

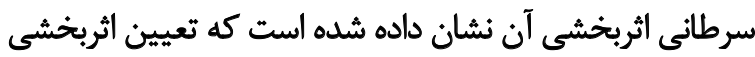

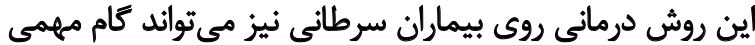

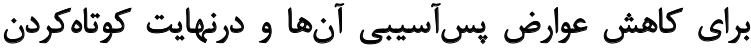

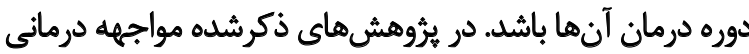

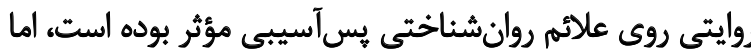

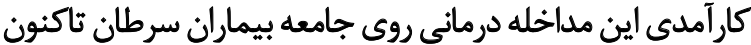

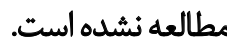

با توجه به اينكه ابتلا به سرطان به عنوان يك حادثه آسيبزا

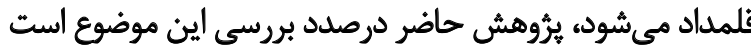

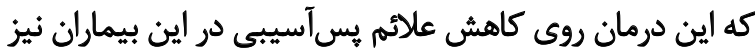

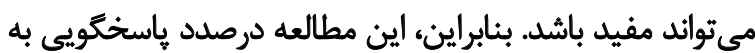

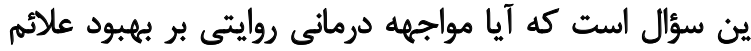

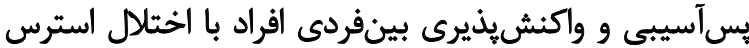

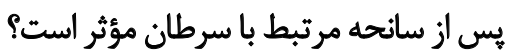

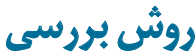

اين بثوهش از نوع تحقيقات آزمايشى با طرح بيش آزمون و

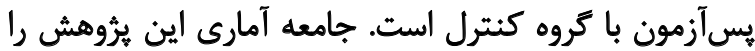

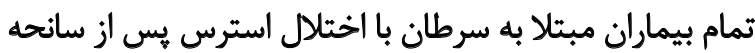

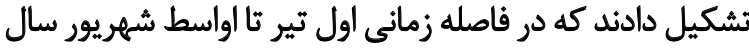

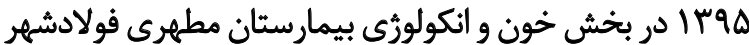

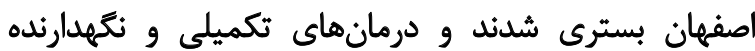

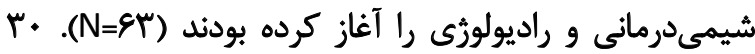

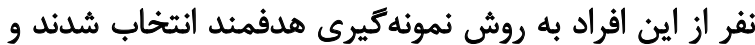

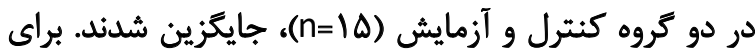

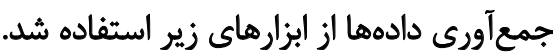

مقياس الخملال استرس يس ازٔ سانحك مي سي سيى 10

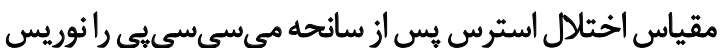

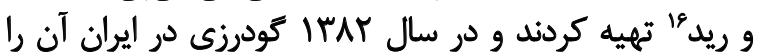

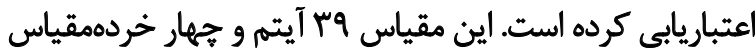

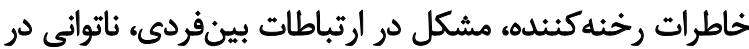

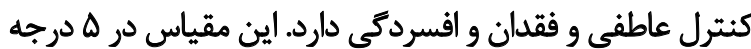

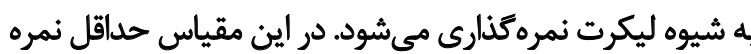

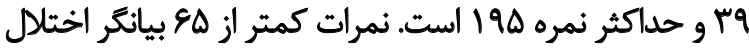

\section{Mississipi}

16. Nourris \& Rid 
ياسخ دادند. براي تجزيه و تحليل دادهها از تحليل كوواريائس جندمتغيرى (مانكوا) استفاده شد.

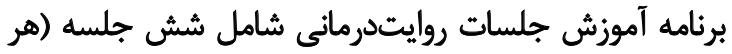

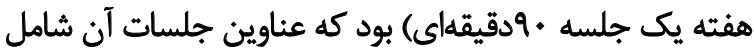

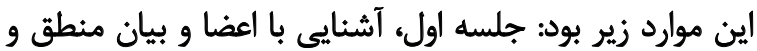

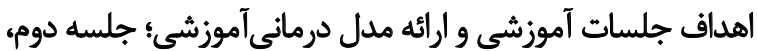

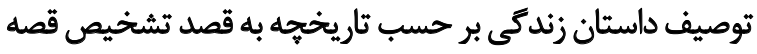

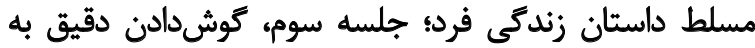

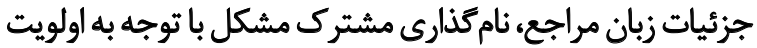

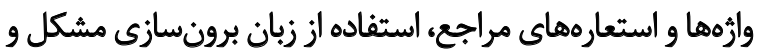

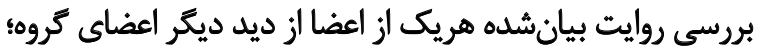

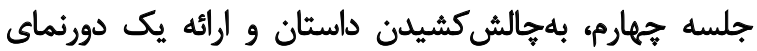

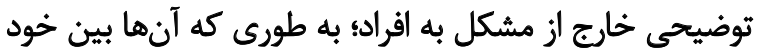

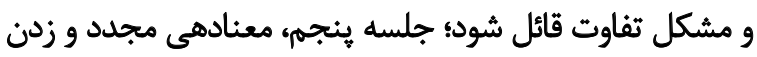

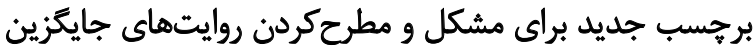
و مرجح، تشويق اعضا به رفتارهاي مغاير با داستان سرشار ازئ جازين
از بين كروه كنترل نيز آنهايي كه در جلسه به بسآزمون

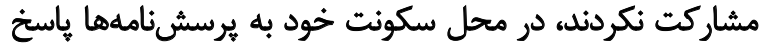

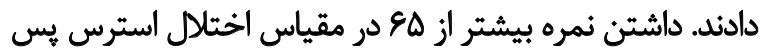

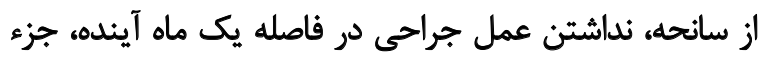

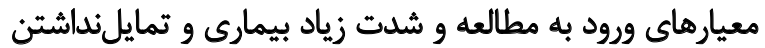

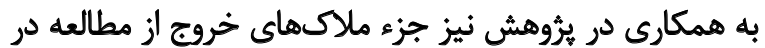

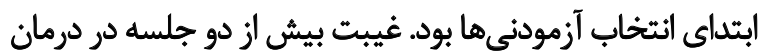

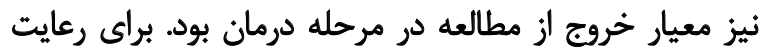

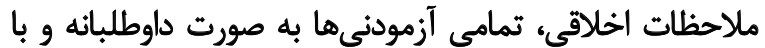

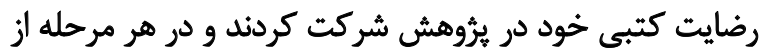

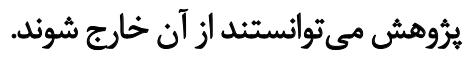

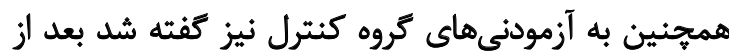

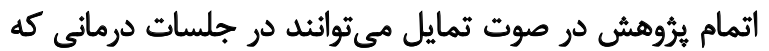

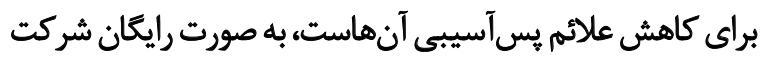

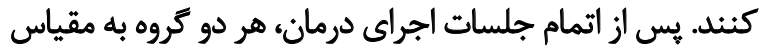

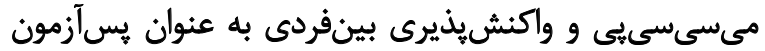

جدول ا. ميانكين و انحراف معيار نمرات بيش آزمون و يّآزمون دو كروه از آزمودنىها در متغيرهاى يُؤهش

\begin{tabular}{|c|c|c|c|}
\hline \multicolumn{2}{|c|}{ ميانكين土 انحراف معيار } & \multirow{2}{*}{ عضويت تروهى } & \multirow{2}{*}{ نوع آزمون } \\
\hline كروه كثترل & كروه آزمايش & & \\
\hline$M / / \pm r / 8$ & $r v / \Delta r \pm v / q$ & خاطرلث رخنه كنينده & \multirow{10}{*}{ ميشش آزمون } \\
\hline$r \Delta / q \pm V /$ & $r N T \pm A / T$ & ارتباطات يين فردى & \\
\hline$r / \Delta \pm \Psi / F$ & $M / T \pm E / N$ & افسردىى و فقدان & \\
\hline$r / q \pm r / V$ & $\nabla / \% \pm \Delta / \varepsilon$ & ثاتوائى در كثترل عاطفه & \\
\hline$I \Psi N Y \pm q / \Delta$ & $|r g| \cdot \pm r r / W \Lambda$ & نمره كلى علاثم يس أسييى & \\
\hline $\mid E / \mathscr{f} \cdot \pm T / \Delta T$ & $|f / A \cdot \pm| /|A|$ & همبلى & \\
\hline $\mid S / N E \pm T / I E$ & $\mid V / I r \pm r / T \varphi$ & خياليردازى & \\
\hline $\mid \Delta / V E \pm T /+\Delta$ & IV/ATIT/TO & داششن ديل وسيع & \\
\hline$|\&| \cdot F \pm \mathbb{H} / N$ & IQET/AY & آسشفنكى شخصى & \\
\hline$\rho \Delta / * \lambda \pm \Delta / V \Delta$ & $R \Psi / N \pm \Phi / H$ & ثمره كلى واكنش يذيرى يه استرس & \\
\hline$r y / r \pm r / r$. & $M \Psi / . \& \pm / N$ & خاطرات رخنه كننده & \multirow{10}{*}{ يس آزمون } \\
\hline$\pi /+E \pm T / N$ & TNYTY/OH & الرتباط بين فردى & \\
\hline$\Gamma / Y \pm \Psi / \&$ & $r e / E \pm \& / T$ & افسردكى و فقدان & \\
\hline$\pi / \Psi \pm \Psi / 8$ & $r \Delta / \Delta \pm \Delta / T$ & ناتوانى در كنترل عاطفه & \\
\hline $\mid r \Delta / r \pm N V^{e}$ & 1../KF士TY/K & نمره كلى علائم هي آسييى & \\
\hline IE/TY士T/K. & $|Q| \cdot Y \pm \Psi / \Delta \varphi^{\prime}$ & همبلى & \\
\hline $\mid Q / \Delta T \pm T / T q$ & $18 / T \cdot \pm T / M$ & خيال يردازى & \\
\hline $\mid \alpha / e 9 \pm T / \varepsilon 8$ & IS/AETR/AD & دانشتن ديد وسيع & \\
\hline $\mid \varepsilon / K \Phi \pm T / 19$ & $|r /| r \pm T / N$. & آشنتكى شخصى & \\
\hline $9 * / 8+ \pm F / 9 \gamma$ & $g \times / \Delta r \pm \Delta / 91$ & نمره كلى واكنشيذيرى به استرس & \\
\hline
\end{tabular}




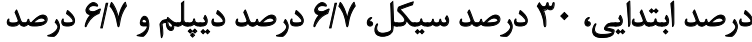

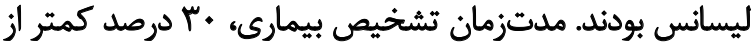

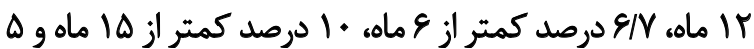

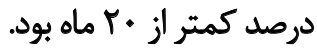

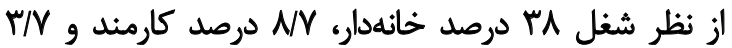

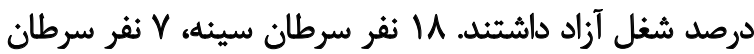

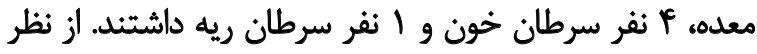

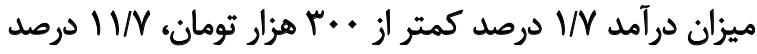

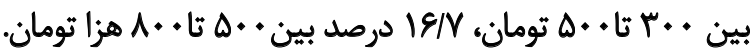

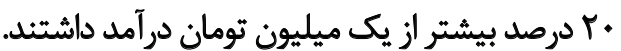

نتايج جدول شماره 1 ميانكين و انحراف معيار نمرات

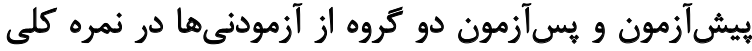

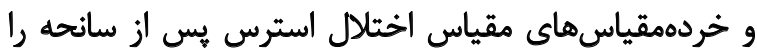

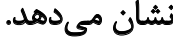

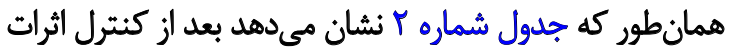

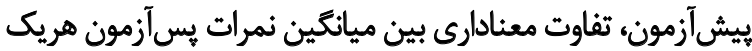

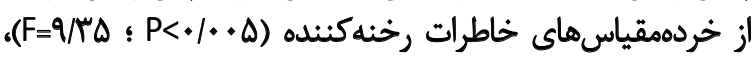

مشكل در فاصله بين جلسات از طريق برسش از مراجع درباره

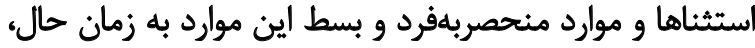
آموزش مهارتهاى حرفزدن (هريك از اعضا خودشان حردان حرف

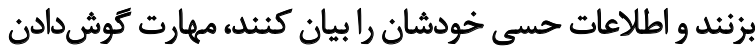

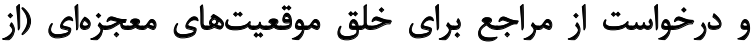

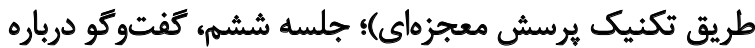

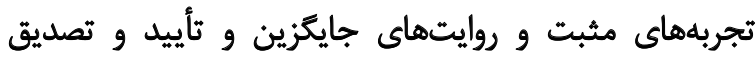

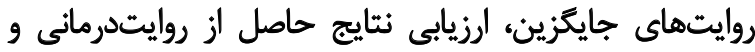

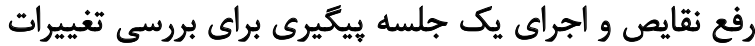

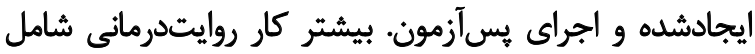

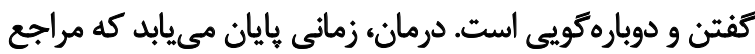

$$
\text { احساس كند روايتش تغيير كرده است. }
$$

يافتهها

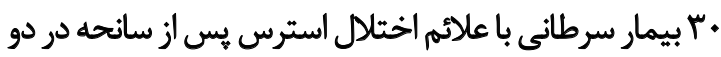

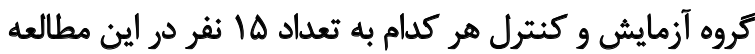

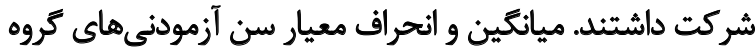

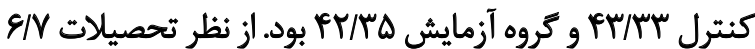

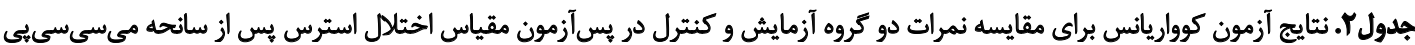

\begin{tabular}{|c|c|c|c|c|c|c|c|c|}
\hline توان آمارى & اتا & $\mathrm{P}$ & $F$ & ميانكين مجذورات & درجه آزادى & مجموع مجذورات & مثغير وابسته & منيع تغيير \\
\hline .1 .0 & $.1+1$ &.$/ 28$ & $.1 .+4$ & $\% \vee$ & 1 & $\% \vee r$ & خاطرات رخنه كنده & \multirow{4}{*}{ اثر ييش آزمون } \\
\hline .1 .9 & $\% 1$ & .10 &.$/ \$ \Delta$ & $8 / 91$ & 1 & $g / 4 \lambda$ & ارتباط بينفردى & \\
\hline.$/ M T$ & $.1 . .9$ & $m$ &.$/ 14$ & $\Delta V / R$ & 1 & $\Delta V / R$ & ناتواتى در كتترل عاطفه & \\
\hline .1 .0 & $\%$ & $\cdot W$ & $\% 1$ & $T / T Q$ & 1 & $r / R \Delta$ & افسردكى و فقدان & \\
\hline •/Ar & $\cdot / \pi \Lambda$ & $\% \Delta$ & a/ro & 119/94 & 1 & 1ิ9/q & خاطراترخثن كننده & \multirow{4}{*}{ صضويت كروهى } \\
\hline.$/ 9$. &.$/ T$ & $\%$ & W/ar & $\mid 85 / .9$ & 1 & $\mid \varepsilon F / .9$ & ارتباطيينفردى & \\
\hline.$/ v 8$ &.$/ T r$ & $\% 1$ & $V / M$ & $119 / \pi$ & 1 & $119 / \pi$ & ناتواثى در كتترل عاطفه & \\
\hline.$/ A F$ & .118 & $\%$ & r/gr & IT/RT & 1 & $\mid r V / q \pi$ & فقدان و افسردكى & \\
\hline
\end{tabular}

جدول ب. نتايج آزمون كوواريانس براى مقايسه نمرات دو كروه در بس آزمون مقياس واكنشيذيرى بينفردى

\begin{tabular}{|c|c|c|c|c|c|c|c|c|}
\hline توان أمارى & ميزان تأثير & معنادارى & $\mathrm{F}$ & ميانكين مجذورات & درجه أزادى & مجموع مجذورات & متغيروإبسته & منيع تغييرات \\
\hline$+1+\Delta$ & ho+t & •/AY & $+1+p q$ & $+/ \Delta S T$ & 1 & PAST & همدلى & \multirow{4}{*}{ اثر ييش آزمون } \\
\hline . /ra & $.1 \% V$ &.$/ M$ & V/Ar & NHI & 1 & NHI & ميالبردازي & \\
\hline .1 &.$/ 0 r$ &.$/ F Y$ & . $/ \Delta T^{\prime}$ & e/ve & 1 & $\varphi / v e$ & هائن ديد وسيع & \\
\hline.$/ 14$ & H.r & E & 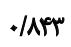 & Ir/at & 1 & $\mid W / a 4$ & آشفتكى شخصي & \\
\hline .194 &.$\pi$ & 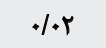 & $\Delta / 91$ & sV/A. & 1 & gV/A. & همدلى & \multirow{4}{*}{ عضويت كروهى } \\
\hline 每 & $.1 \cdot V^{e}$ &.$/ \% 9$ & $\cdot / M^{e}$ & גוא & 1 & גוא & خيال بيردأزى & \\
\hline.$/ .14$ & . & ع & " & V/eer & 1 & VRer & داشتن ديل وسيع & \\
\hline$\cdot / r$ & $+R \Delta$ & $+/+1$ & $V / 91$ & ITNIVI & 1 & ITNIVI & آشفتكى شخصى & \\
\hline
\end{tabular}

توانبخننى 
جدول ع. نتايج آزمون كوواريانس براى مقايسه نمرات كلى دو كروه در يس آزمون استرس يس از سانحه واكنشيذيرى بينفردى

\begin{tabular}{|c|c|c|c|c|c|c|c|c|}
\hline توان آمارى & ميزان تأثير & معنادارى & $\mathrm{F}$ & ميانكين مجذورات & درجه آزادى & مجذوروع & متغير وابسته & منبع تغييرات \\
\hline .1 .0 & $.1 . .1$ &.$/ A V$ & $\% r$ & r/ar & 1 & r/ar & استرس يس أز ساتحه & \multirow{2}{*}{ اثر ييش أزمون } \\
\hline זו/. & 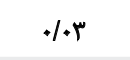 & .149 & . Na & $\pi / / F$ & 1 & Tr/IF & واكنشيذيرى بينفردى & \\
\hline.$/ I r$ & $.1+r$ & .1 .1 & $.18 \Delta$ & $1 \cdots / r$ & 1 & $1 . . / r$ & استرس يس از سانحه & \multirow{2}{*}{ عضويت كروهى } \\
\hline$\% \Delta$ & $.1 . .1$ &.$/ 9$. &.$/ 1$ & . las & 1 & .199 & واكنشيذيرى بينفردى & \\
\hline
\end{tabular}

سانحه مرتبط با سرطان دارد و موجب بهبود علائم فيزيولوريك

مرتبط با استرس در اين زنان شد بـ [آس].

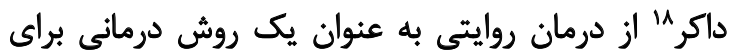

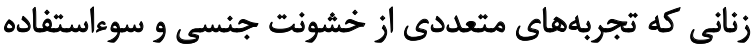

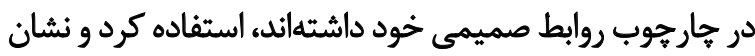

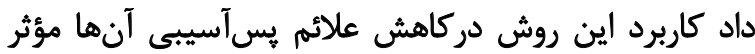

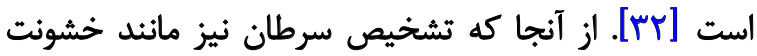

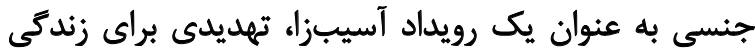

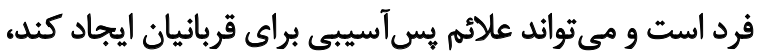

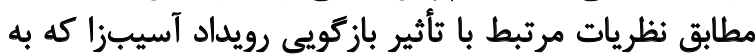

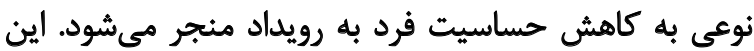

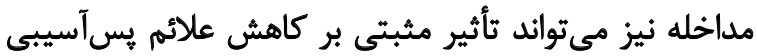

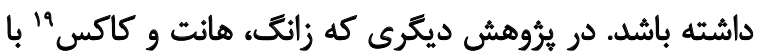

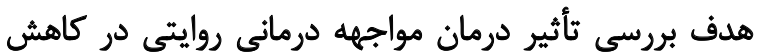

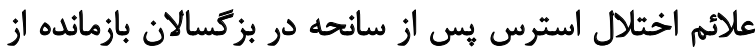

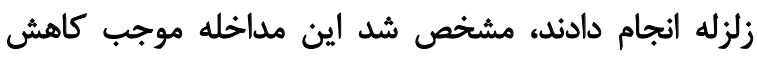

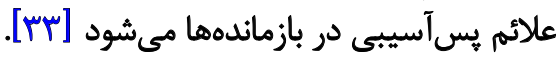

وجود خاطرات مزاحم و نشخواركنينده در افراد مبتلا به سرطان

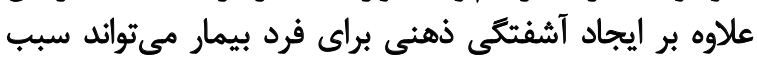

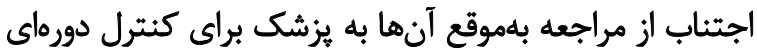

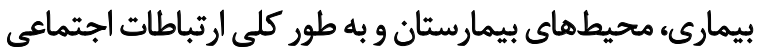

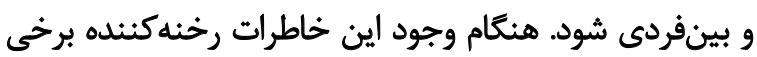

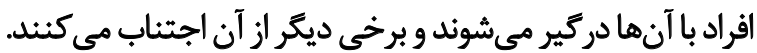

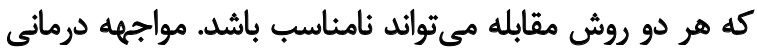

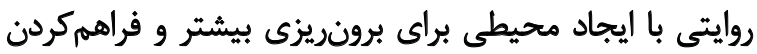

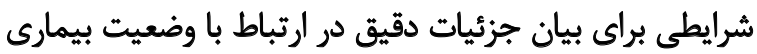
فرد، مىتواند بار هيجانى را براى فرد دركير با بيمارى كمتر كنيات باندي افرادى كه تحت يك رويداد آسيبزايى نظير تشخيص سرطان

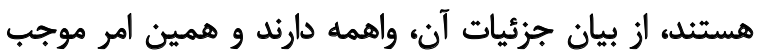

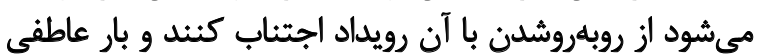

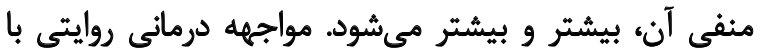

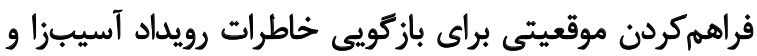

18. Daucker

19. Zang, Hunt \& Cox

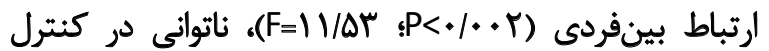
عاطفه (F= (F=V/MA

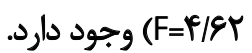

مطابق جدول شماره ب نتايج تحليل كوواريانس نشان مي دهد كه

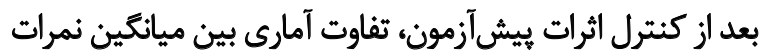

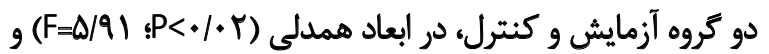

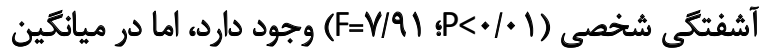

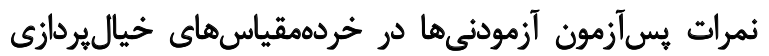

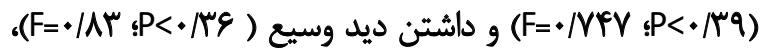
تفاوت معنادارى بين ميانكين دو كروه به دست نئ نيامد

مطابق جدول شماره F، نتايج تحليل كوواريانس نشان مي بدهي

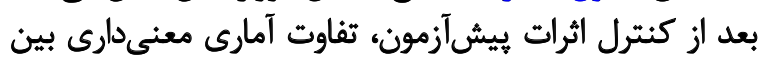

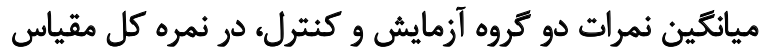

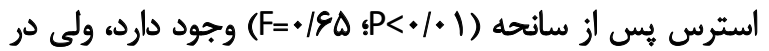

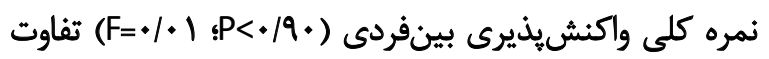
آمارى معنادارى بين ميانگين دو كروه به دست نياميند

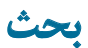

ابتلا به سرطان بسيار ناراحت كنيده است و موقعيتى

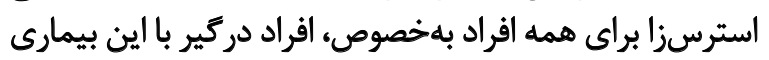

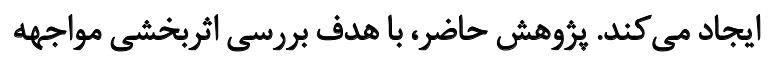

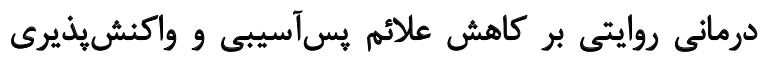

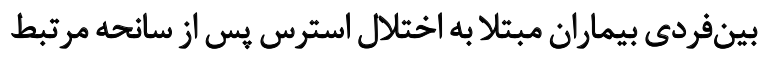

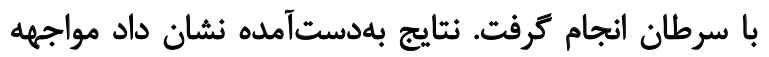

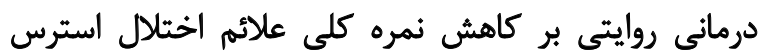

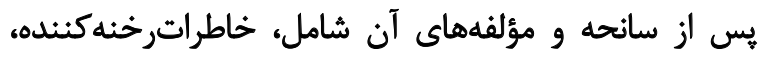

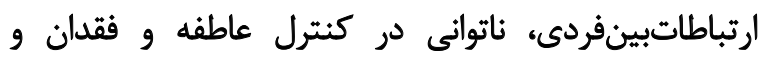

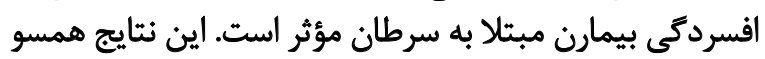

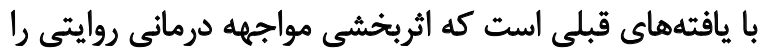

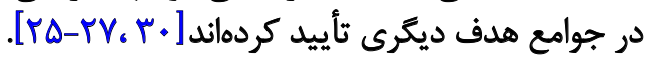

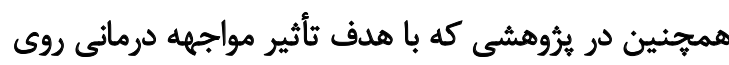

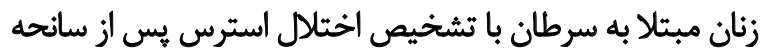

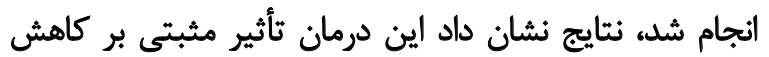

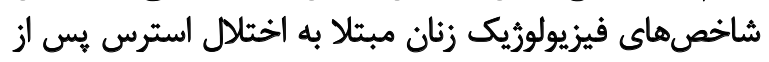


كلى واكنشيذيرى به استرس اثربخش نبوده است. اين نتايج

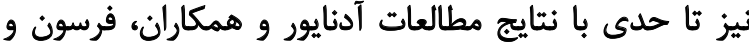

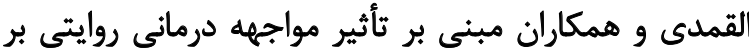

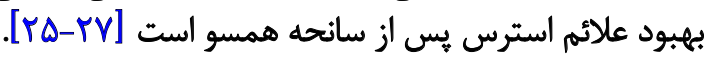

در تبيين اثربخشى مواجهه درمانى روايتى بر خردمدمقياس

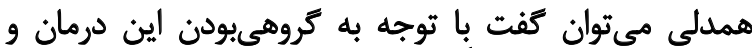

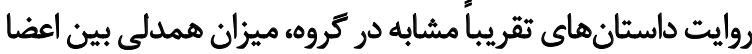

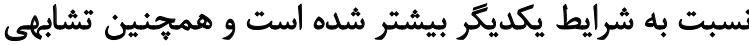

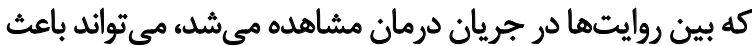

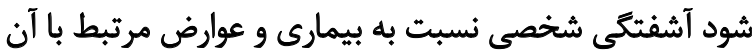

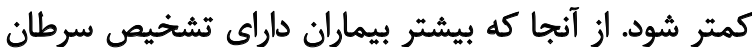

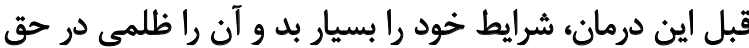

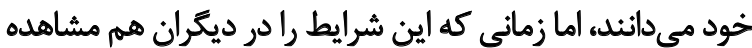

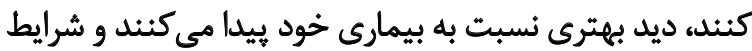
ييشآمده براى خود را بهنجار سازى مى كنيند.

نتيجليرى

درمجموع نتايج اين مطالعه نشان داد مواجهه درمانى روايتى

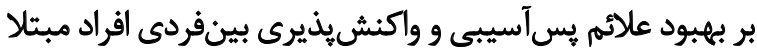

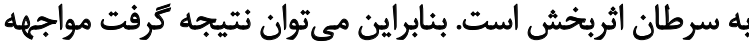

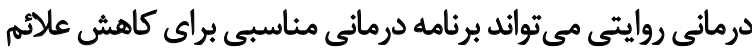

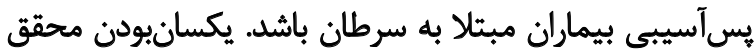

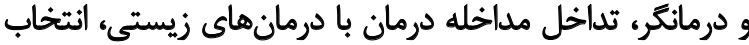

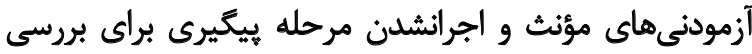

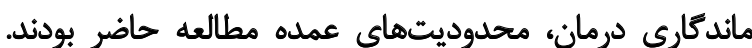

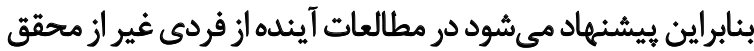

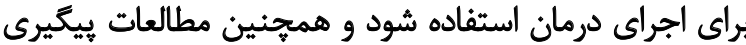

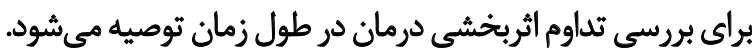
براى افزايش تعميميذيرى نتايج از آزمودنهاى مذكر نيز

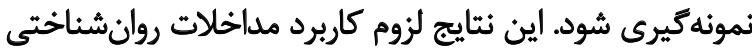

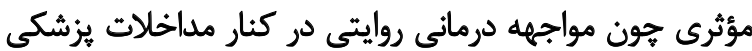

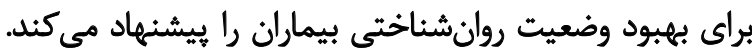

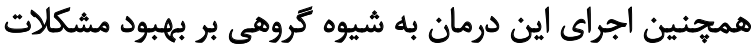

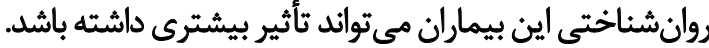

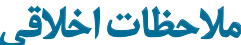

\section{ييروى از اصول اخلاق يثوهش}

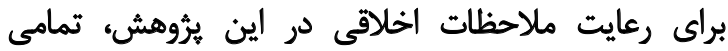

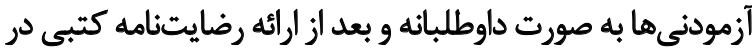

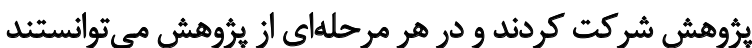

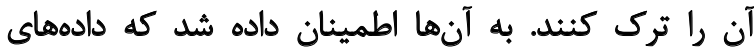
جمعآورى شده از آنها به صورت تروهى تحليل شده ودر اختيار انديار
تكرار آنها در يك جوّ آرام و بدون تنش مي تواند در كاهش علائم منفى رويداد آسيبزا مؤثر باشد.

مواجهه درمانى روايتى مى تواند بسترى فراهم كند ثا افراد

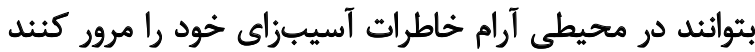

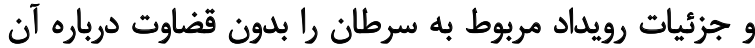

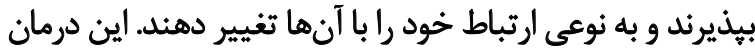

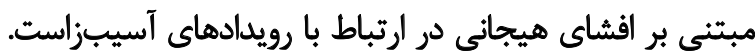

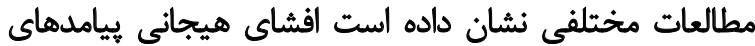

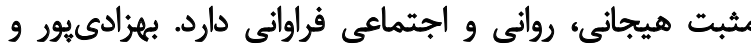

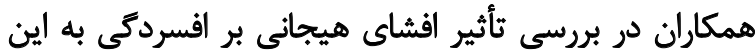

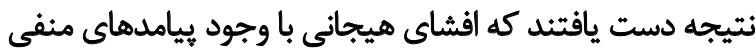

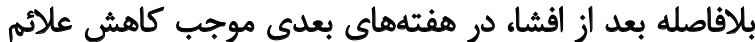

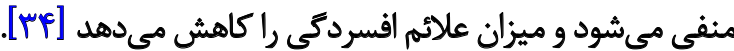

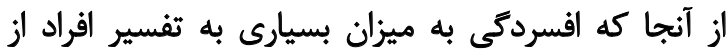

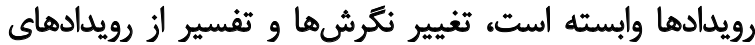

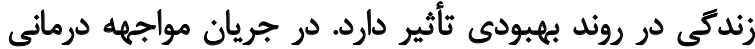

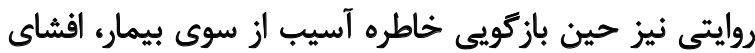

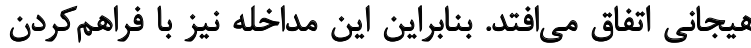

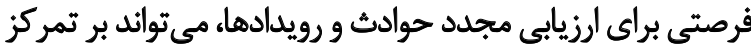

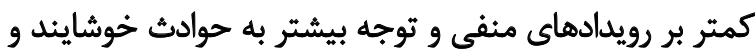

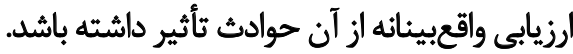

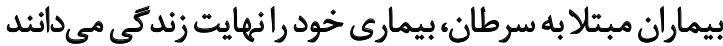

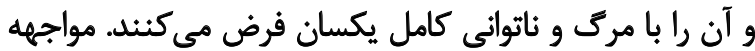

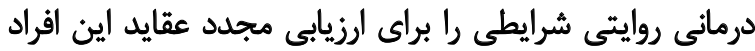

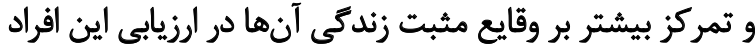

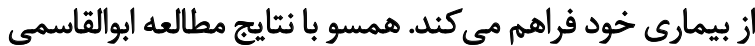

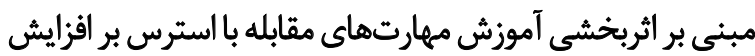

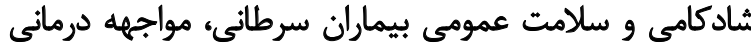

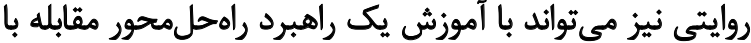

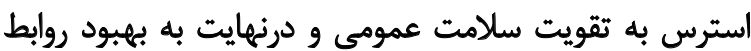

بينفردى بيماران منجر شود [ـاهـ]

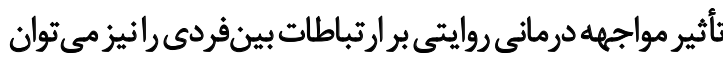

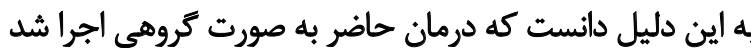

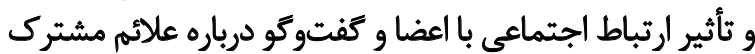

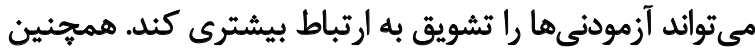

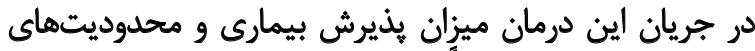

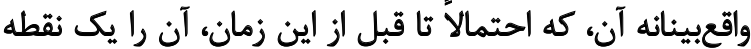

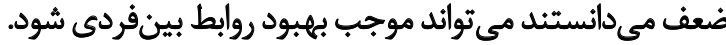
نتايج تحليل كوواريانس جندمتغيرى نشان داد مواجهه

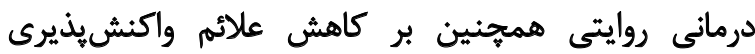

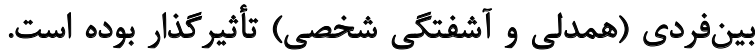

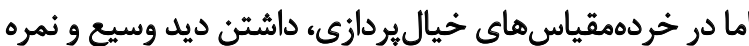


شخُص ثالثى قرار داده نخواهد شد.

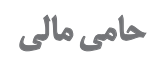

اين مقاله مستخرج از باياننامه نويسنده دوم مقاله، شعله

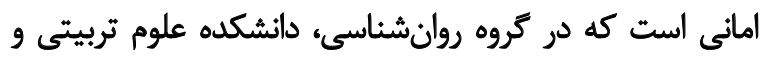

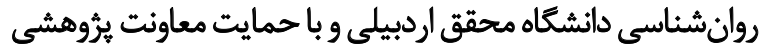
دانشكاه محقق اردبيلى انجام شده است إني

$$
\text { مشاركت نويسئد مَان }
$$

مفهومسازى: سجاد بشريور: تحقيق و بررسى: شعله امانى؛

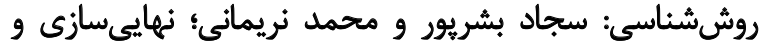

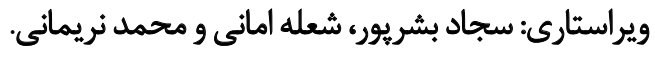

$$
\text { تعارض مناقع }
$$

بنابر اظهار نويسندكان، اين مقاله تعارض منافع ندارد. 


\section{References}

[1] American Cancer Society. Cancer facts \& figures 2010. Atlanta: American Cancer Society; 2010.

[2] Macdonald F, Ford Ch, Casson A. Molecular biology of cancer. London:Taylor \& Francis; 2004. [DOI:10.4324/9780203503447]

[3] Hasanpour A. [Quality of life and related factors in cancer Patients under chimical therapy of oncology hospital of tehran university of medical science (Persian)]. Journal of Kermanshah University of Medical Sciences. 2006; 10(2):110-9

[4] Kangas M, Milross C, Bryant RA. A brief, early cognitive-behavioral program for cancer-related PTSD, anxiety, and comorbid depression. Cognitive and Behavioral Practice. 2014; 21(4):416-31.[DOI:10.1016/j.cbpra.2014.05.002]

[5] Parikh D, De leso P, Garvey G, Thachil T, Ramamoorthi R, Penniment $M$, Jayaraj R. Post-traumatic stress disorder and post-traumatic growth in breast cancer patients- A systematic review. Asian Pacific Journal of Cancer Prevention. 2015; 16(2):641-6

[6] American Psychiatric Association. Diagnostic and statistical manual of mental disorders Washington: American Psychiatric Association; 2000.

[7] Andrykowski MA, Kangas M. Posttraumatic stress disorder associated with cancer diagnosis and treatment. In: Holland JC, Breitbart WS, Jacobsen PB, Lederberg MS, Loscalzo MJ, McCorkle R, editors. Psycho-oncology. Oxford: Oxford University Press; 2010.

[8] Khosravi P, Moradi A, Jenabian A. [The effects of cognitive therapy based on mindfulness on decreasing the symptoms of post traumatic stress disorder and increasing the autobiographical memory in treated patients with breast cancer (Persian)]. Culture Counseling. 2013; 18(5):63-80.

[9] Sadock B, Ruiz P. Kaplan \& Sadock's synopsis of psychiatry: Behavioral sciences. New York: Walters Kluwer; 2015.

[10] Hayes SC, Strosahl K, Wilson KG, Bissett RT, Pistorello J, Toarmino $D$, et al. Measuring experiential avoidance: A preliminary test of a working model. The Psychological Record. 2004; 54(4):553-78. [DOI:10.1007/BF03395492]

[11] Smith JM. Depressive rumination as experiential avoidance [PhD. dissertation]. Philadelphia: Temple University; 2008.

[12] Benedict C, Penedo FJ. Psychosocial interventions in cancer. In: Carr BI, Steel J, editors. Psychological Aspects of Cancer. Berlin: Springer; 2013. [DOI:10.1007/978-1-4614-4866-2_14]

[13] Morphew ME. The future of human performance and stress research: A new challenge. In Hancock PA, Desmond PA, editors. Stress, Workload, and Fatigue. Didcot: Taylor \& Francis; 2001.

[14] Sandler IN, Tein JY, Mehta P, Wolchik S, Ayers T. Coping efficacy and psychological problems of children of divorce. Child Development. 2000; 71(4):1099-118. [DOI:10.1111/14678624.00212] [PMID]

[15] Benight CC, Harper M L. Coping self-efficacy perceptions as a mediator between acute stress response and long-term distress following natural disasters. Journal of Trauma Stress. 2002; 15(3):177-86. [DOI:10.1023/A:1015295025950] [PMID]

[16] Tirtashi ENK. [Efficacy of narrative therapy on willingness to forgive in womens (persian)]. Clinical Psychology. 2012; $4(2): 88-71$.

[17] Maghsoodi S, Salehinejad Z. [The relationship between socia support and quality of life among cancer patients in Kerman (Persian)]. Quarterly Journal of Social Work. 2018; 7(2):15-22.

[18] Nakhjovani HA, Badri Gargari R. [Efficacy of methods of emotional disclosure (verbal/writing) to improve the quality of life in women with breast cancer (Persian)]. Urmia University of Medical Sciences. 2015; 26(6):519-30.

[19] Ma'arefvand M, Khatamsaz Z. [Coping strategies of the parents of the children with cancer (Persian)]. Journal of Social Work. 2014; 3(3):3-9.

[20] Izadi-Ajirlo A, Bahmani B, Ghanbari-Motlagh A. [Effectiveness of cognitive behavioral group intervention on body image improving and increasing self-esteem in women with breast cancer after mastectomy (Persian)]. Archives of Rehabilitation. 2013; 13(4):72-83.

[21] Amani O, Mazaheri M A, Nejati V, Shamsian BS. [Effect of cognitive rehabilitation on executive functions in adolescent survivors of Leukemia: A randomized and controlled clinical trial (Persian)]. Journal of Rehabitionation. 2017; 18(1):73-82. [DOI:10.21859/jrehab-180173]

[22] Ghamari-Givi H, Fathi A, Senobar L. [The effectiveness of the combination of mental imagination and massage therapy on anger in children with cancer (Persian)]. Journal of Rehabition. 2014; 14(4):26-34

[23] Kucukogly S, Celebioglu A. Identification of psychological symptoms and associated factors in adolescents who have a parent with cancer in Turkey. European Journal of Oncology Nursing. 2013; 17(1):75-80. [DOI:10.1016/j.ejon.2011.10.008] [PMID]

[24] Goldenkreutz DM, Andersen BL. Depressive symptoms after breast cancer surgery: Relationships with global, cancer-related, and life event stress. Journal of Psychooncology. 2004; 13(3):211-20. [DOI:10.1002/pon.736] [PMID] [PMCID]

[25] Adenauer H, Catani C, Gola H, Keil J, Ruf M, Schauer M, et al. Narrative exposure therapy for PTSD increases top-down processing of aversive stimuli-evidence from a randomized controlled treatment trial. BMC Neuroscience. 2011; 12:127. [DOI:10.1186/1471-2202-12-127] [PMID] [PMCID]

[26] McPherson J. Does narrative exposure therapy reduce PTSD in survivors of mass violence? Research on Social Work Practice. 2012; 22(1):29-42. [DOI:10.1177/1049731511414147]

[27] Alghamdi M, Hunt $N$, Thomas $S$. The effectiveness of narrative exposure therapy with traumatised firefighters in Saudi Arabia: A randomized controlled study. Behaviour Research and Therapy. 2015; 66:64-71. [DOI:10.1016/j.brat.2015.01.008] [PMID]

[28] Goodarzi MA. [Evaluating validity and reliability of Mississipp Post Traumatic stress disorder scale (Persian)]. Journal of Psychology. 2004; 7(2):153-78. 
[29] Davis MH. Measuring individual differences in empathy: Evidence for a multidimensional approach. Journal of Personality and Social Psychology. 1983; 44(1):113-26. [DOI:10.1037//0022-3514.44.1.113]

[30] Salehi M, Shariati A, Ansari M, Latifi M. [Effec of Beneson relaxation the performance measuresof quality of life in breast cancer patients receiving chemotherapy (Persian)]. Jundishapur Journal of Chronic Disease Care. 2011; 9(6):76-89.

[31] Basharpoor S, Amani SH, Narimani M \& Heidary F. [The effectiveness of narrative exposure therapy on improving the stress physiological indexes in women with cancer (Persian)]. Health Psychology. 2018; 7(1):133-45

[32] Daucker B. Narrative therapy for women who have lived with violence. Archives of Psychiatric Nursing. 1998; 12(6):162-8. [DOI:10.1016/S0883-9417(98)80018-6]

[33] Zang Y, Hunt N, Cox T. A randomised controlled pilot study: the effectiveness of narrative exposure therapy with adult survivors of the Sichuan earthquake. BMC Psychiatry. 2013; 13:41. [DOI:10.1186/1471-244X-13-41] [PMID] [PMCID]

[34] Behzadipour S, Sepah Mansour M, Keshavarzi Arshadi F, Farzad V, Naziri Gh, Zamanian Gh. [Effectiveness of stress management based on cognitive-behavioral intervention on guality of life and coping styles for female with breast cancer (Persian)]. Methods and Psychological Models. 2013; 3(12):29-46.

[35] Abolghsemi S. [The efficacy of emotional intelligence teaching and coping strategies for stress training on general health and happiness of cancer patients (Persian)]. Journal of Social Work. 2017; 6(3):32-40. 